\title{
Marijuana use and sex with multiple partners among lesbian, gay and bisexual youth: results from a national sample
}

Xiaoyun Zhang ${ }^{1^{*}}$ and Li-Tzy Wu W $^{2,3} 4^{*}$

\begin{abstract}
Background: Sex with multiple partners (SMP) is one of the important contributing factors for contracting sexually transmitted infections (STIs) among adolescents and young adults, especially among Lesbian, Gay, and Bisexual (LGB) youth. Past studies mainly focus on examining associations of alcohol or club drugs use with unprotected sexual behaviors among adult homo/bisexual men, while little is known about the temporal association between marijuana use (MU) and SMP among LGB youth.

Methods: This study examined the relationship between MU and SMP among LGB adolescents and young adults. Generalized estimating equations (GEE) logistic regression analyses were utilized to analyze four waves' public-use Add Health data ( $N=694$, youth who reported a homo/bisexual status at any wave; Wave 1: aged 11-21; Wave 4: aged 24-32).

Results: After adjusting for other substance use, current depression, mother-child relationship quality at Wave 1, and socioeconomic variables, past-year MU was both concurrently and prospectively associated with past-year SMP. The moderating effect of age was not found.

Conclusion: MU is concurrently and prospectively associated with increased odds of SMP in the adolescent sample and in the young adult sample. Findings imply that prevention/intervention on HIV risk behaviors may benefit from MU reduction not only in LGB adolescents but also in young adults.
\end{abstract}

Keywords: Marijuana use, Sex with multiple partners, Lesbian, Gay, Bisexual youth

\section{Background}

Lesbian, Gay, and Bisexual (LGB) youth are at risk for some health conditions. For example, 80\% of youth aged 13-24 with a new HIV diagnosis in 2014 were males who selfidentified gay or bisexual [1]. Also, lesbian and bisexual girls are more likely to report unintended pregnancy compared with their heterosexual peers [2]. Higher risks of STIs, including HIV, among homo/bisexual males and unintended pregnancy rate among lesbian and bisexual females may be related to unprotected or risky sexual behaviors such as sex with multiple partners (SMP). Compared to heterosexual youth (11.1\%), a higher proportion of LGB 9th-12th graders reported having 4+ lifetime sexual

\footnotetext{
* Correspondence: xzhang@huskers.unl.edu; litzy.wu@duke.edu

${ }^{1}$ General Motors, Detroit, Ml 48265, USA

${ }^{2}$ Department of Psychiatry and Behavioral Sciences, School of Medicine,

Duke University Medical Center, BOX 3903, Durham, NC 27710, USA

Full list of author information is available at the end of the article
}

partners (gay/lesbian: 29.9\%; bisexual: 28.2\%) [3]. To decrease risk of SMP among LGB youth, identifying risk factors to inform prevention is critical.

MU and SMP may co-occur among LGB youth. Similar to SMP, LGB youth are at risk for MU. National survey data showed that $34.5 \%$ gay/lesbian and $36.8 \%$ of bisexual 9th-12th graders reported current MU compared with $21.8 \%$ heterosexual students [1]. Further, compared to heterosexual youth, LGB youth not only had higher initial rates of substance use including use of marijuana, but the substance use prevalence also increased more rapidly during transition from adolescence to young adulthood [4]. Also, a number of studies have documented positive associations between MU and SMP among the general samples without differentiating sexual orientations [5]; further, the strength of the associations has been found to be stronger among adolescents than young adults [6]. Past 
studies on LGB population have focused mainly on examining associations of alcohol or club drugs use with unprotected sexual behaviors among adult homo/bisexual men [7]. However, the temporal association between MU and SMP among LGB youth is unclear. To date, many states in the United States have legalized marijuana for medical use, with some for recreational use. Legalization of MU may increase marijuana availability, which raises concerns about $\mathrm{MU}$ and its related problems [8]. Given high prevalence of $\mathrm{MU}$ [3], it is critical to understanding the relationship between MU and SMP in this young population. This study examines concurrent and prospective associations between past-year MU and SMP among LGB youth. We also examine whether the concurrent association is moderated by age group. We examine two hypotheses: 1) MU is positively associated with SMP in LGB youth; 2) the strength of the associations is stronger in adolescence than young adulthood.

\section{Methods}

\section{Data source}

Data were from four waves' public-use Add Health datasets $(N=3342)$. Add Health was a longitudinal study of a national sample of 7th-12th graders during 1994-1995 academic years [9]. From September 1994 to April 1995, over 90,000 students from 132 schools (80 high schools and 52 middle schools) completed in-school questionnaires; and then the eligible students participated in-home interview (Wave 1, $N=$ 20,745 , age $=11-21,79 \%$ of response rate). In 1996, students in grades $7-11$ at Wave 1 were followed up for the second in-home interview (Wave 2; $N=$ 14,738 , age $=11-21,88.6 \%$ of response rate). Two other in-home interviews were followed between $\mathrm{Au}$ gust 2001 and April 2002 (Wave 3; $N=15,170$, age = $18-26,77.4 \%$ response rate), and during 2008-2009 (Wave 4; $N=15,701$, age $=24-32,80.3 \%$ response rate). Through in-home interviews, longitudinal survey data on the social, economic, psychological, and health circumstances were obtained, with Wave 1-2 constituting the adolescence period and Wave 3-4 focusing on the emerging and young adulthood [10]. Audio-CASI technology (audio-computer assisted selfinterview) was used for sensitive health status and behavioral health-related questions to enhance the quality of self-reporting of sensitive and illegal information [10]. Study designs and procedures were described in detail in [10].

A total of 3342 participants that represented a random sample from the total sample were made available for public use (see guidelines for analyzing Add Health data, [9, 11]). The analysis sample included those who reported a homo/bisexual status at any wave $(N=694 ; 21.5 \%$ of public-use sample; $72.2 \%$ females; $68.5 \%$ non-Hispanic Whites, $12.8 \%$ nonHispanic Blacks, $11.7 \%$ Hispanics and $6.7 \%$ nonHispanic others). At Wave 1, 45.7\% of respondents' resident mothers and $35.6 \%$ of the fathers had $12+$ years' education; $22.3 \%$ of the families received pastmonth welfare. The use of de-identified Add Health datasets was declared exempt from review by the Duke University Health System Institutional Review Board.

\section{Measures}

MU referred to "ever use" at Wave 1; and "past-year use" at Wave 2-4.

Past-year number of sexual partners referred to the number of having sexual relationships at Wave 1 and Wave 2 (since the date of last interview). At Wave 3, it referred to having vaginal intercourse; and at Wave 4, it included the number of female/male partners having sexual activities. The variables were dichotomized into having any sexual partner (ASP: $0=0$ partner, $1=1+$ partners $)$ and SMP $(0=0-1$ partner, $1=2+$ partners $)$.

Covariates at eave wave included other types of substance use (i.e., current smoking: referring to those smoking at least 1 day during the past 30 days and ever smoking regularly; past-year alcohol use: no use, monthly use, and weekly use; other illegal drug use: lifetime use at Wave 1 and 4, past-year use at Wave 2 , and past- 6 years use at Wave 3 , including included cocaine, inhalants, crystal meth, LSD, PCP, ecstasy, mushrooms, ice, heroin, or prescription medicines not prescribed to respondents), and current CES-D depression (9-item version of CES-D; score of $10+$ indicating having depression [12]). Covariates at Wave 1 included mother-child relationship quality (5 items; 5likert scale, the Cronbach'alpha $=0.84$; scores of 20 or higher as high quality [13]), gender, age cohort, race/ ethnicity, mother and father's education level, and whether family receiving welfare. Previous findings indicate that use of other substances [7] was associated with MSP among young men who have sex with men, and that race/ethnicity [14], socioeconomic status [15], depression [16], and mother-child relationship [17] are associated with SMP among study samples without differentiating sexual orientations. We include these variables as control variables.

\section{Data Analysis}

GEE analyses were conducted using Stata 13.0. First, we obtained concurrent unadjusted and adjusted odds ratios (AORs) and 95\% confidence intervals (CIs). Second, we tested the interaction effect between MU and wave on SMP. Third, we examined whether prior MU (one-wave lagged MU) predicted increased odds of later SMP. The independent working correlation 
structure was specified [18]. Grand sample weights were included to make the estimates from the national sample generalizable.

\section{Results}

Table 1 summarizes prevalence of MU and ASP/SMP. Approximately $30 \%$ of LGB youth used marijuana in the past year in 1995 and 1996. The proportions increased to $45.3 \%$ in $2001-2002$, and decreased to $32.4 \%$ in 2008-2009. About 15\% of LGB youth reported having more than 1 partners in 1995 and 1996. The proportions increased to more than $30 \%$ at Wave $3(31.6 \%)$ and 4
(38.0\%). Additional analyses indicated that, compared with heterosexual youth, proportions of MU in LGB youth were higher at each wave; proportions of SMP were higher at Wave 2 and 4, but not at Wave 1 and 3 (footnotes under Table 1).

In the unadjusted analysis, past-year $\mathrm{MU}$ was associated with past-year SMP $(\mathrm{OR}=2.79,95 \% \mathrm{CI}=2.22$, 3.51; Table 2). Past-year MU remained modestly associated with increased odds of SMP after adjusting for covariates $(\mathrm{AOR}=1.55,95 \% \mathrm{CI}=1.18,2.04$; Table 3$)$. The interaction effect of MU and wave on SMP was insignificant (Table 4). Further analysis indicated that prior MU was

Table 1 Weighted prevalence and 95\% Confidence Interval (CI) of substance use and number of sexual partners, and weighted means and standard errors (SE) for current CES-D depression, as well as mother-child relationship at Wave 1

\begin{tabular}{|c|c|c|c|c|}
\hline$N=694^{\mathrm{ab}}$ & Wave 1 & Wave 2 & Wave 3 & Wave 4 \\
\hline Year of Survey & 1995 & 1996 & $2001-2002$ & 2008-2009 \\
\hline Age range & $11-21$ & $13-21$ & $18-27$ & $24-32$ \\
\hline Prevalence \% (95\% Cl) & $\%(95 \% \mathrm{Cl})$ & $\%(95 \% \mathrm{Cl})$ & $\%(95 \% \mathrm{Cl})$ & $\%(95 \% \mathrm{Cl})$ \\
\hline \multicolumn{5}{|l|}{${ }^{\circ}$ Past-Year Marijuana Use } \\
\hline Yes & $30.3(26.0-34.9)$ & $33.9(29.8-38.3)$ & $45.3(40.0-50.6)$ & $32.4(28.4-36.7)$ \\
\hline \multicolumn{5}{|l|}{ Past-Year Alcohol Use } \\
\hline No use & $50.0(44.9-55.2)$ & $46.6(42.4-50.8)$ & 23.3(18.9-28.4) & 19.8(16.4-23.8) \\
\hline$\leq$ Monthly use & $42.2(37.2-47.4)$ & $41.5(37.8-45.4)$ & $47.6(43.2-52.2)$ & 44.7(39.9-49.6) \\
\hline Weekly use & $7.8(6.0-10.2)$ & 11.8(9.5-14.6) & $28.9(24.0-34.2)$ & $35.4(30.1-41.1)$ \\
\hline \multicolumn{5}{|l|}{ Current Smoking } \\
\hline Yes & $20.9(17.4-24.9)$ & 23.4(19.8-27.4) & $39.9(35.2-44.9)$ & $43.5(39.1-48.0)$ \\
\hline \multicolumn{5}{|c|}{ Ever Other Illegal Drug Use } \\
\hline Yes & $18.2(14.1-23.1)$ & 13.3(10.5-16.7) & $42.0(37.3-46.8)$ & $50.0(45.2-55.0)$ \\
\hline \multicolumn{5}{|c|}{ Past-Year Having Any Sexual Partners } \\
\hline Yes & 24.0(19.9-28.7) & 21.2(17.7-25.3) & $77.9(73.4-81.8)$ & $88.9(86.1-91.2)$ \\
\hline \multicolumn{5}{|c|}{ 'Past-Year Having Multiple Sexual Partners } \\
\hline Yes & $15.9(13.0-19.4)$ & $15.7(12.7-19.4)$ & $31.6(27.8-35.8)$ & $38.0(32.8-43.4)$ \\
\hline \multicolumn{5}{|c|}{ Current CES-D Depression } \\
\hline Mean (SE) & $6.62(6.23-7.00)$ & $6.89(6.52-7.25)$ & $5.97(5.60-6.34)$ & $6.61(6.21-7.02)$ \\
\hline Cronbach' alpha & 0.80 & 0.83 & 0.84 & 0.83 \\
\hline \multicolumn{5}{|c|}{ Mother-Child Relationship-W1 } \\
\hline Range & $8-25$ & & & \\
\hline Mean (SE) & 20.6(20.3-21.0) & & & \\
\hline Cronbach'alpha & 0.85 & & & \\
\hline
\end{tabular}

${ }^{a}$ Homo/bisexual respondents, $n=694$ : at Wave 1 and 2, Add Health data provided at most nine sexual partners' gender information for each respondent. Another question was added to ask about if respondents had any other partners additionally. Respondents who had at least one same-sex partner were identified as homo/bisexual cases. At Wave 3, those who identified themselves totally homosexual, mostly homosexual, equally homosexual or heterosexual, mostly heterosexual, were defined as homo/bisexual cases. At Wave 4, similar to Wave 3, those who did not identified themselves as totally heterosexual were defined as homo/bisexual cases. Furthermore, respondents who reported the number of same-sex partners (even 0 ) were identified as homo/bisexual cases

${ }^{\mathrm{b}}$ The percentages of missing data on the studied variables ranged from 0 to $1.4 \%$, except for mother-child relationship quality (4.8\%, mostly due to no resident mother at home), and number of sexual partners at Wave 4 (5.8\%, program error)

c, We used "svy: tab" commands in Stata to examine whether the proportions of marijuana use (MU) and sex with multiple partners (SMP) at each wave were significantly different between homo/bisexual youth and their heterosexual counterparts. The design-based results were following: MU: $F(1130)=12.17$ $($ Wave 1$) ; F(1130)=24.55($ Wave 2$) ; F(1130)=21.07($ Wave3); $F(1130)=37.15($ Wave 4$) ; p<.001$. SMP: $F(1130)=2.32, p>.05($ Wave 1$) ; F(1130)=6.75, p<.05$ (Wave 2); $F(1130)=1.74$ (Wave 3); $p>.05 ; F(1130)=24.63, p<.001$. Prevalence (\%) of MU from Wave 1 to 4 among heterosexual youth: $22.9,23.4,32.9,21.4$; SMP: $13.6 ; 11.8 ; 28.6 ; 23.7$ 
Table 2 Generalized estimating equations (GEE): Unadjusted longitudinal logistic regression analysis of each studied variable and number of sexual partners (OR and $95 \% \mathrm{Cl}, N=694$ )

\begin{tabular}{|c|c|c|}
\hline Independent variables & Having Any Sexual Partner (Wave 1 to 4) & Having Multiple Sexual Partners (Wave 1 to 4) \\
\hline \multicolumn{3}{|l|}{ Past-Year Marijuana Use } \\
\hline & $2.15(1.79-2.59)^{c}$ & $2.79(2.22-3.51)^{c}$ \\
\hline \multicolumn{3}{|l|}{ Past-Year Alcohol Use } \\
\hline$\leq$ monthly use vs. no use & $2.77(2.22-3.47)^{c}$ & $2.21(1.68-2.89)^{c}$ \\
\hline weekly use vs. no use & $6.80(5.12-9.04)^{c}$ & $5.05(3.72-6.86)^{c}$ \\
\hline \multicolumn{3}{|l|}{ Current Smoking } \\
\hline & $3.48(2.84-4.26)^{c}$ & $2.97(2.35-3.74)^{c}$ \\
\hline \multicolumn{3}{|l|}{ Ever Other Illegal Drug Use } \\
\hline & $4.33(3.51-5.33)^{c}$ & $3.05(2.48-3.75)^{c}$ \\
\hline Current CES-D $(\geq 10=1)$ & $1.33(1.08-1.64)^{b}$ & $1.49(1.17-1.90)^{b}$ \\
\hline Mother-Child Relationship-W1 $(\geq 20=1)$ & $0.71(0.60-0.85)^{c}$ & $0.75(0.58-0.96)^{a}$ \\
\hline Gender $($ male $=1)$ & $0.88(0.72-1.07)$ & $1.25(0.97-1.61)$ \\
\hline \multicolumn{3}{|l|}{ Age group in years } \\
\hline $15-17$ vs. $11-14$ & $1.46(1.24-1.72)^{c}$ & $1.37(1.09-1.74)^{b}$ \\
\hline $18^{+}$vs. $11-14$ & $2.06(1.45-2.94)^{c}$ & $1.38(0.83-2.28)$ \\
\hline \multicolumn{3}{|l|}{ Race/Ethnicity } \\
\hline Hispanic vs. Non-Hispanic White & $1.11(0.89-1.39)$ & $0.80(0.54-1.19)$ \\
\hline Non-Hispanic Black vs. Non-Hispanic White & $1.57(1.25-1.98)^{c}$ & $1.82(1.38-2.39)^{\mathrm{c}}$ \\
\hline Non-Hispanic Others vs. Non-Hispanic White & $1.06(0.76-1.48)$ & $1.50(0.93-2.42)$ \\
\hline \multicolumn{3}{|l|}{ Respondent's Mother Education Level } \\
\hline college or more vs. high school and below & $0.79(0.67-0.93)^{b}$ & $0.92(0.72-1.17)$ \\
\hline missing vs. high school and below & $0.97(0.71-1.32)$ & $1.04(0.69-1.56)$ \\
\hline \multicolumn{3}{|l|}{ Respondent's Father Education Level } \\
\hline college or more vs. high school and below & $0.85(0.69-1.04)$ & $0.96(0.72-1.28)$ \\
\hline missing vs. high school and below & $1.04(0.84-1.29)$ & $1.10(0.82-1.48)$ \\
\hline \multicolumn{3}{|l|}{ Family Receiving Welfare-W1 } \\
\hline yes vs. no & $0.98(0.79-1.21)$ & $1.08(0.82-1.41)$ \\
\hline missing vs. no & $1.01(0.80-1.28)$ & $0.99(0.72-1.38)$ \\
\hline
\end{tabular}

$a_{<.05}$

$\mathrm{b}<.01$

$c<.001$

modestly associated with increased odds of later SMP $(\mathrm{AOR}=1.42,95 \% \mathrm{CI}=1.07,1.89$; Table 5$)$.

\section{Discussion}

This study examined the temporal relationship between MU and SMP in a national sample of LGB youth. Pastyear MU was concurrently and prospectively associated with increased odds of past-year SMP after adjusting for covariates, and the strength of concurrent associations was similar in the adolescent sample and the young adult sample. It implies that prevention/intervention on SMP may benefit from MU reduction in both LGB adolescents and young adults. These findings are inconsistent with those found from the general population sample that included both heterosexual and homo/bisexual youth in the analysis, as the later found that the strength of associations between MU and SMP decrease by age as adolescence transitioned to young adulthood [6]. This analysis provided new findings for LGB youth because prior studies have focused on adult homo/bisexual men, in which significant associations between $\mathrm{MU}$ and unprotected sexual behaviors were inconsistently found [7]. Specifically, prior studies tended to employ convenience samples drawn from men attending gay bars/clubs or sex parties, who might use various illicit drugs with 
Table 3 Generalized estimating equations (GEE): Adjusted longitudinal logistic regression analysis of marijuana use and number of sexual partners (AOR and 95\% Cl, N=694 ${ }^{\mathrm{ab}}$ )

\begin{tabular}{|c|c|c|}
\hline Independent variables & Having Any Sexual Partner (Wave 1 to 4) & Having Multiple Sexual Partners (Wave 1 to 4) \\
\hline \multicolumn{3}{|l|}{ Past-Year Marijuana Use } \\
\hline & $0.85(0.65-1.10)$ & $1.55(1.18-2.04)^{b}$ \\
\hline \multicolumn{3}{|l|}{ Past-Year Alcohol Use } \\
\hline$\leq$ monthly use vs. no use & $2.32(1.82-2.97)^{c}$ & $1.81(1.36-2.41)^{c}$ \\
\hline weekly use vs. no use & $4.96(3.48-7.07)^{c}$ & $3.37(2.42-4.69)^{c}$ \\
\hline \multicolumn{3}{|l|}{ Current Smoking } \\
\hline & $2.33(1.77-3.06)^{c}$ & $1.87(1.42-2.47)^{c}$ \\
\hline \multicolumn{3}{|l|}{ Ever Other Illegal Drug Use } \\
\hline & $3.05(2.34-3.98)^{c}$ & $1.91(1.47-2.47)^{c}$ \\
\hline${ }^{c}$ Current CES-D $(\geq 10=1)$ & $0.84(0.64-1.11)$ & $1.16(0.85-1.57)$ \\
\hline dMother-Child Relationship-W1 $(\geq 20=1)$ & $0.89(0.70-1.12)$ & $0.94(0.70-1.25)$ \\
\hline Gender $($ male $=1)$ & $0.82(0.65-1.04)$ & $1.23(0.93-1.63)$ \\
\hline \multicolumn{3}{|l|}{ Age group in years } \\
\hline $15-17$ vs. $11-14$ & $1.29(1.05-1.57)^{\mathrm{a}}$ & $1.17(0.90-1.51)$ \\
\hline $18^{+}$vs. $11-14$ & $1.62(1.02-2.55)^{\mathrm{a}}$ & $0.81(0.45-1.48)$ \\
\hline \multicolumn{3}{|l|}{ Race/Ethnicity } \\
\hline Hispanic vs. Non-Hispanic White & $1.17(0.91-1.49)$ & $0.81(0.56-1.17)$ \\
\hline Non-Hispanic Black vs. Non-Hispanic White & $2.76(2.08-3.66)^{c}$ & $3.09(2.18-4.40)^{c}$ \\
\hline Non-Hispanic Others vs. Non-Hispanic White & $1.08(0.73-1.61)$ & $1.66(0.95-2.88)$ \\
\hline \multicolumn{3}{|l|}{ Respondent's Mother Education Level } \\
\hline college or more vs. high school and below & $0.84(0.67-1.04)$ & $0.89(0.67-1.19)$ \\
\hline missing vs. high school and below & $0.77(0.45-1.32)$ & $0.80(0.48-1.32)$ \\
\hline \multicolumn{3}{|l|}{ Respondent's Father Education Level } \\
\hline college or more vs. high school and below & $0.75(0.58-0.98)^{\mathrm{a}}$ & $0.83(0.60-1.15)$ \\
\hline missing vs. high school and below & $0.90(0.69-1.16)$ & $0.87(0.62-1.20)$ \\
\hline \multicolumn{3}{|l|}{ Family Receiving Welfare-W1 } \\
\hline yes vs. no & $0.83(0.66-1.04)$ & $0.99(0.72-1.35)$ \\
\hline missing vs. no & $0.72(0.53-0.98)^{a}$ & $0.97(0.67-1.39)$ \\
\hline
\end{tabular}

$a_{<}<.05$

$\mathrm{b}<.01$

$c<.001$

sex [7]. Our sample was drawn from a national sample of LGB youth, thus findings may have a greater generalizability than results from convenience samples. Additionally, we examined the association of MU and SMP in a younger LGB sample. Focusing on adolescents and young adults is important to inform prevention. Early MU and SMP may have a devastating impact on health. For example, prevalence MU disorder among users of $\mathrm{MU}$ is generally higher among adolescents/youth than adults [19]. Early SMP is linked with STIs, unwanted pregnancies, and poverty [20]. Early prevention/intervention is critically needed to prevent adverse outcomes in adulthood.
Using the data from a national sample, we found that the prevalence of past-year MU and SMP among LGB youth were higher than those among heterosexual youth, suggesting that LGB youth are at higher risk for MU and SMP [3]. Two theories may explain the link between MU and SMP [21]. First, MU may increase risk for SMP through impairing young users' decision-making or judgement. Second, MU and SMP may be influenced by certain shared risk factors (e.g., LGB-relate stressors, other substance use). Compared with heterosexual youth, LGB youth reported a higher prevalence of mental health problems [22], childhood sexual/physical abuse, and peer victimization [23]. They may engage in 
Table 4 Generalized estimating equations (GEE): Testing the interaction effect between marijuana use and wave on number of sexual partners (AOR and 95\% Cl, N=694)

\begin{tabular}{|c|c|c|}
\hline Independent variables & Having Any Sexual Partner (Wave 1 to 4) & Having Multiple Sexual Partners (Wave 1 to 4 ) \\
\hline Past-Year Marijuana Use & $1.34(0.76-2.36)$ & $2.34(1.43-3.81)^{\mathrm{b}}$ \\
\hline Wave (Wave1 =0) & $3.84(3.20-4.62)^{c}$ & $1.50(1.27-1.76)^{c}$ \\
\hline \multicolumn{3}{|l|}{ Past-Year Marijuana Use $\times$ Wave } \\
\hline & $1.01(0.74-1.37)$ & 0.87(0.69-1.09) \\
\hline \multicolumn{3}{|l|}{ Past-Year Alcohol Use } \\
\hline$\leq$ monthly use vs. no use & $1.70(1.23-2.33)^{b}$ & $1.56(1.17-2.09)^{b}$ \\
\hline weekly use vs. no use & $2.10(1.39-3.18)^{c}$ & $2.51(1.81-3.49)^{c}$ \\
\hline \multicolumn{3}{|l|}{ Current Smoking } \\
\hline & $1.93(1.37-2.71)^{c}$ & $1.68(1.27-2.22)^{c}$ \\
\hline \multicolumn{3}{|l|}{ Ever Other Illegal Drug Use } \\
\hline & $1.82(1.34-2.49)^{\mathrm{c}}$ & $1.54(1.16-2.05)^{\mathrm{b}}$ \\
\hline Current CES-D $(\geq 10=1)$ & $1.04(0.76-1.44)$ & $1.24(0.92-1.66)$ \\
\hline Mother-Child Relationship-W1 $(\geq 20=1)$ & $0.78(0.59-1.04)$ & $0.92(0.69-1.24)$ \\
\hline Gender $($ male $=1)$ & $0.79(0.58-1.08)$ & $1.24(0.93-1.64)$ \\
\hline \multicolumn{3}{|l|}{ Age group in years } \\
\hline $15-17$ vs. $11-14$ & $1.62(1.24-2.10)^{c}$ & $1.20(0.92-1.55)$ \\
\hline $18^{+}$vs. $11-14$ & $2.26(1.15-4.45)^{\mathrm{a}}$ & $0.87(0.46-1.63)$ \\
\hline \multicolumn{3}{|l|}{ Race/Ethnicity } \\
\hline Hispanic vs. Non-Hispanic White & $1.13(0.81-1.58)$ & $0.80(0.55-1.18)$ \\
\hline Non-Hispanic Black vs. Non-Hispanic White & $2.83(1.92-4.16)^{c}$ & $2.89(2.02-4.12)^{c}$ \\
\hline Non-Hispanic Others vs. Non-Hispanic White & $1.02(0.60-1.75)$ & $1.66(0.95-2.92)$ \\
\hline \multicolumn{3}{|l|}{ Respondent's Mother Education Level } \\
\hline college or more vs. high school and below & $0.71(0.53-0.95)^{\mathrm{a}}$ & $0.87(0.65-1.16)$ \\
\hline missing vs. high school and below & $0.59(0.31-1.10)$ & $0.77(0.46-1.31)$ \\
\hline \multicolumn{3}{|l|}{ Respondent's Father Education Level } \\
\hline college or more vs. high school and below & $0.78(0.55-1.11)$ & $0.86(0.62-1.20)$ \\
\hline missing vs. high school and below & $0.94(0.67-1.31)$ & $0.89(0.64-1.24)$ \\
\hline \multicolumn{3}{|l|}{ Family Receiving Welfare-W1 } \\
\hline yes vs. no & $0.73(0.53-1.01)$ & $0.99(0.72-1.35)$ \\
\hline missing vs. no & $0.66(0.45-0.99)^{a}$ & $0.99(0.68-1.43)$ \\
\hline
\end{tabular}

$\mathrm{a}_{<}<.05$

${ }^{b}<.01$

${ }^{c}<.001$

self-sabotaging behaviors like MU and SMP to escape from these traumatic issues and emotional distress [24]. Future studies may test the two theories simultaneously using one comprehensive model, or test possible mechanisms (e.g., MU outcome expectancy) between MU and SMP.

The study has limitations. SMP was not measured consistently across waves. It may help to explain no significant differences found in the proportions of SMP between heterosexual and LGB youth at Wave 1 and 3 . Interpretation of results should be with caution.
Researchers should measure the same construct consistently across measurement points. Second, this study relied on self-report measures of MU and SMP, potential measurement errors and age-related changes in reporting behaviors might exist and confound the results [6]. Thirdly, we only used past-year SMP as an indicator of risky sexual behaviors. If youth who have multiple partners at a given time but use condoms consistently, they are at a lower risk for contracting STIs. However, available data indicate that having a higher number of sexual partners is associated with a lower 
Table 5 Generalized estimating equations (GEE): Adjusted longitudinal logistic regression analysis of one-wave lagged effect of marijuana use and number of sexual partners (AOR and $95 \% \mathrm{Cl}, \mathrm{N}=694$ )

\begin{tabular}{|c|c|c|}
\hline Independent variables & Having Any Sexual Partner (Wave 1 to 4) & Having Multiple Sexual Partners (Wave 1 to 4) \\
\hline \multicolumn{3}{|l|}{ Lagged (Past-Year Marijuana Use) } \\
\hline & $1.35(1.01-1.81)^{*}$ & $1.42(1.07-1.89)^{*}$ \\
\hline \multicolumn{3}{|l|}{ Past-Year Alcohol Use } \\
\hline$\leq$ monthly use vs. no use & $2.04(1.57-2.67)^{* * *}$ & $1.91(1.38-2.63)^{* * *}$ \\
\hline weekly use vs. no use & $3.42(2.33-5.02)^{* * *}$ & $3.41(2.39-4.87)^{* * *}$ \\
\hline \multicolumn{3}{|l|}{ Current Smoking } \\
\hline & $2.12(1.56-2.88)^{* * *}$ & $1.70(1.28-2.27)^{* * *}$ \\
\hline \multicolumn{3}{|l|}{ Ever Other IIlegal Drug Use } \\
\hline & $2.92(2.18-3.90)^{* * *}$ & $1.81(1.36-2.40)^{* * *}$ \\
\hline Current CES-D $(\geq 10=1)$ & $0.76(0.55-1.05)$ & $1.25(0.91-1.71)$ \\
\hline Mother-Child Relationship-W1 $(\geq 20=1)$ & $0.90(0.71-1.15)$ & $0.96(0.70-1.31)$ \\
\hline Gender $($ male $=1)$ & $0.80(0.61-1.04)$ & $1.36(1.00-1.85)$ \\
\hline \multicolumn{3}{|l|}{ Age group in years } \\
\hline $15-17$ vs. $11-14$ & $1.20(0.97-1.48)$ & $0.98(0.74-1.29)$ \\
\hline $18^{+}$vs. $11-14$ & $1.21(0.68-2.16)$ & $0.71(0.37-1.40)$ \\
\hline \multicolumn{3}{|l|}{ Race/Ethnicity } \\
\hline Hispanic vs. Non-Hispanic White & $1.30(0.98-1.73)$ & $0.83(0.55-1.25)$ \\
\hline Non-Hispanic Black vs. Non-Hispanic White & $2.78(2.03-3.80)^{* * *}$ & $2.99(2.07-4.31)^{* * *}$ \\
\hline Non-Hispanic Others vs. Non-Hispanic White & $1.16(0.75-1.79)$ & $1.95(1.11-3.44)^{*}$ \\
\hline \multicolumn{3}{|l|}{ Respondent's Mother Education Level } \\
\hline college or more vs. high school and below & $0.84(0.67-1.07)$ & $0.91(0.67-1.24)$ \\
\hline missing vs. high school and below & $0.94(0.50-1.76)$ & $0.82(0.47-1.41)$ \\
\hline \multicolumn{3}{|l|}{ Respondent's Father Education Level } \\
\hline college or more vs. high school and below & $0.85(0.63-1.14)$ & $0.93(0.65-1.31)$ \\
\hline missing vs. high school and below & $1.03(0.78-1.37)$ & $1.00(0.70-1.42)$ \\
\hline \multicolumn{3}{|l|}{ Family Receiving Welfare-W1 } \\
\hline yes vs. no & $0.83(0.65-1.07)$ & $1.06(0.77-1.47)$ \\
\hline missing vs. no & $0.76(0.52-1.10)$ & $1.04(0.73-1.48)$ \\
\hline
\end{tabular}

${ }^{*}<.05,{ }^{* * *}<.001$

prevalence of condom use [25]. Thus, SMP may serve as one of the important indicators of risky sexual behaviors. Despite these limitations, this study is among the first to examine the temporal relationship between MU and SMP over time among LGB youth.

\section{Conclusions}

In conclusion, this study examined both the concurrent association and prospective association between pastyear MU and past-year SMP in a national LGB adolescents and young adults. Findings indicate that past-year MU is both concurrently and prospectively associated with past-year SMP, while the concurrent associations between the two do not vary over time. Prevention and intervention efforts aimed at reducing SMP in LGB youth may benefit from reduction of MU both in adolescence and young adulthood.

\section{Abbreviations}

ASP: Having any sexual partner; CES-D: Center for Epidemiologic Studies Depression Scale; GEE: Generalized estimating equations; LGB: Lesbian, gay and bisexual; MU: Marijuana use; SMP: Sex with multiple partners;

STIs: Sexually transmitted infections

\section{Acknowledgments}

We would like to thank Add Health's investigators, research staff, collaborators, and participants.

\section{Funding}

This work was made possible by research support from the U.S. National Institutes of Health (UG1DA040317, R01MD007658, R01DA019623, PI,

Li-Tzy Wu). The sponsoring agency had no further role in the study design and analysis, the writing of the report, or the decision to submit the paper for publication. The opinions expressed in this paper are solely those of the authors. 


\section{Availability of data and materials}

The analysis dataset for this manuscript is available from Xiaoyun Zhang on reasonable request.

\section{Authors' contributions}

XZ contributed to study designs, conducted data analyses, and drafted the manuscripts. L-TW contributed to study designs and analyses, drafted the manuscripts, and supervised the work. Both authors read and approved the final manuscript.

\section{Competing interests}

The authors declare that they have no competing interests.

\section{Consent for publication}

Not applicable.

\section{Ethics approval and consent to participate}

According to the Add Health public-use data information, Add Health participants provided written informed consent for participation in all aspects of Add Health in accordance with the University of North Carolina School of Public Health Institutional Review Board guidelines.

The use of de-identified Add Health datasets for this manuscript was declared exempt from review by the Duke University Health System Institutional Review Board.

\section{Author details}

'General Motors, Detroit, Ml 48265, USA. ${ }^{2}$ Department of Psychiatry and Behavioral Sciences, School of Medicine, Duke University Medical Center, BOX 3903, Durham, NC 27710, USA. ${ }^{3}$ Department of Medicines, School of Medicine, Duke University, Durham, NC, USA. ${ }^{4}$ Duke Clinical Research Institute, Duke University Medical Center, Durham, NC, USA.

\section{Received: 9 February 2016 Accepted: 6 December 2016} Published online: 05 January 2017

\section{References}

1. Center for Disease Control and Prevention. Diagnoses of HIV infection in the United States and Dependent Areas, 2014. HIV Surveillance Report 2014. http://www.cdc.gov/hiv/library/reports/surveillance/. Published November 2015. Accessed 29 July 2016.

2. Goodenow C, Szalacha LA, Robin LE, Westheimer K. Dimensions of sexual orientation and HIV-related risk among adolescent females: Evidence from a statewide survey. Am J Public Health. 2008;98:1051-8.

3. Center for Disease Control and Prevention. Sexual identity, sex of sexual contacts, and health-risk behaviors among students in Grade 9-12: Youth Risk Behavior Surveillance, selected sites, United States, 2001-2009. MMWR. 2011;60(7):1-51.

4. Marshal MP, Friedman MS, Stall R, Thompson AL. Individual trajectories of substance use in lesbian, gay and bisexual youth and heterosexual youth. Addiction. 2009;104:974-81.

5. Cavazos-Rehg PA, Krauss MJ, Spitznagel EL, Schootman M, Cottler LB, Bierut L. Number of sexual partners and associations with initiation and intensity of substance use. AID Behav. 2011;15:869-74.

6. Vasilenko SA, Lanza ST. Predictors of multiple sexual partners from adolescence through young adulthood. J Adolesc Health. 2014;55(4):491-7.

7. Vosburgh HW, Mansergh G, Sullian PS, et al. A review of the literature on event-level substance use and sexual risk behavior among men who have sex with men. AIDS Behav. 2012;16:1394-410.

8. Levy S. Effects of marijuana policy on children and adolescents. JAMA Pediatr. 2013;167(7):600-2.

9. Harris KM, Udry JR. National Longitudinal Study of Adolescent Health (Add Health), 1994-2008. ICPSR21600-v12. Ann Arbor, Ml: Inter-university Consortium for Political and Social Research [distributor], 2013-03-08. doi:10.3886/ICPSR21600.v12.

10. Harris KM. The Add Health Study: Design and accomplishments. 2013. http://www.cpc.unc.edu/projects/addhealth/data/guides/DesignPaperWIIV. pdf. Accessed 22 Jan 2014

11. Chen P, Chantala K. Guidelines for analyzing Add Health data. 2014. Retrieved on Mar 17. 2016 from http://www.cpc.unc.edu/projects/ addhealth/data/guides/wt-guidelines.pdf. Accessed 17 Mar 2016.
12. Boardman JD, Alexander KB. Stress trajectories, health behaviors, and the mental health of black and white young adults. Soc Sci Med. 2011;72:1659-66.

13. Bynum MS, Kotchick BA. Mother-adolescent relationship quality and autonomy as predictors of psychosocial adjustment among African American adolescents. J Child Fam Stud. 2006;15:529-42.

14. Nakamura N, Dawe M, McGuire F, Rudzinski K, Jones W, Rehm J, Fischer B. Gender differences in cannabis use related characteristics in high frequency using Canadian university students: An exploratory study. Womens Health Urban Life. 2011;10(2):81-93.

15. Chandra A, Billioux VG, Copen CE, Sionean C. HIV risk-related behaviors in the United States household populations aged 15-44 years: Data from the National Survey of Family Growth, 2002 and 2006-2010. National health statistics reports; no 46. Hyattsville: National Center for Health Statistics; 2012.

16. Turner AK, Latkin C, Sonenstein F, Tandon D. Psychiatric disorder symptoms, substance use, and sexual risk behavior among African-American out of school youth. Drug Alcohol Depend. 2011;115:67-73.

17. Kincaid C, Jones DJ, Sterrett E, McKee L. A review of parenting and adolescent sexual behavior: The moderating role of gender. Clin Psychol Rev. 2012;32:177-88.

18. Diggle PJ, Heagerty P, Liang K-Y, et al. Analysis of longitudinal data. 2nd ed. Oxford: Oxford University Press; 2002.

19. Wu L-T, Brady KT, Mannelli P, Killeen TK, NIDA AAPI Workgroup. Cannabis use disorders are comparatively prevalent among nonwhite racial/ethnic groups and adolescents: A national study. J Psychiatr Res. 2014;50:26-35.

20. Rector RE, Johnson KA, Noyes LR, et al. The harmful effects of early sexual activity and multiple sexual partners among women: A book of charts. Washington: The Heritage Foundation; 2003.

21. King KM, Nguyen HV, Kosterman R, et al. Co-occurrence of sexual risky behaviors and substance use across emerging adulthood: Evidence for state-and trait-level associations. Addiction. 2012;107:1288-96.

22. Lewis NM. Mental health in sexual minorities: Recent indicators, trends, and their relationships to place in North America and Europe. Health Place. 2009;15:1029-45.

23. Friedman MS, Marshal MP, Guadamuz TE, et al. A meta-analysis of disparities in childhood sexual abuse, parental physical abuse, and peer victimization among sexual minority and sexual nonminority individuals. Am J Public Health. 2011;101:1481-94.

24. Jerome RC, Halkitis PN, Siconolfi DE. Club drug use, sexual behavior, and HIV seroconversion: A qualitative study of motivations. Subst Use Misuse. 2009; 44:431-47.

25. Elkington KS, Bauermeister JA, Zimmerman MA. Do parents and peers matter? A prospective socio-ecological examination of substance use and sexual risk among African American youth. J Adolesc. 2011;34:1035-47.

\section{Submit your next manuscript to BioMed Central and we will help you at every step:}

- We accept pre-submission inquiries

- Our selector tool helps you to find the most relevant journal

- We provide round the clock customer support

- Convenient online submission

- Thorough peer review

- Inclusion in PubMed and all major indexing services

- Maximum visibility for your research

Submit your manuscript at www.biomedcentral.com/submit
Biomed Central 